\title{
Epidemiological Features and Trends of Brown Spot of Pear Disease Based on the Diversity of Pathogen Populations and Climate Change Effects
}

\author{
Concepció Moragrega, Mireia Puig, Lídia Ruz, Emilio Montesinos, and Isidre Llorente†
}

All authors: Institute of Food and Agricultural Technology-XaRTA-CIDSAV, University of Girona, C/ Maria Aurèlia Capmany, 61, 17003 Girona Spain.

Accepted for publication 22 September 2017.

\begin{abstract}
Brown spot of pear, caused by the fungus Stemphylium vesicarium, is an emerging disease of economic importance in several pear-growing areas in Europe. In recent years, new control strategies combining sanitation practices and fungicide applications according to developed forecasting models have been introduced to manage the disease. However, the pathogenic and saprophytic behavior of this pathogen makes it difficult to manage the disease. In addition, climate change can also result in variations in the severity and geographical distribution of the disease. In this study, ecological and epidemiological aspects of brown spot of pear disease related to inoculum characterization and climate change impact were elucidated. The pathogenic variation in S. vesicarium populations from pear orchards and its relationship to inoculum sources (air samples, leaf debris, and infected host and nonhost tissues) was determined using multivariate analysis. In total, six variables related to infection and disease development on cultivar Conference pear detached leaves of $110 \mathrm{~S}$. vesicarium isolates were analyzed. A high proportion of isolates $(42 \%)$ were nonpathogenic to pear; $85 \%$ of these nonpathogenic isolates were recovered from air samples. Most isolates

recovered from lesions (93\%) and pseudothecia (83\%) were pathogenic to pear. A group of pathogenic isolates rapidly infected cultivar Conference pear leaves resulted in disease increase that followed a monomolecular model, whereas some $S$. vesicarium isolates required a period of time after inoculation to initiate infection and resulted in disease increase that followed a logistic model. The latter group was mainly composed of isolates recovered from pseudothecia on leaf debris, whereas the former group was mainly composed of isolates recovered from lesions on pear fruit and leaves. The relationship between the source of inoculum and pathogenic/aggressiveness profile was confirmed by principal component analysis. The effect of climate change on disease risk was analyzed in two pear-growing areas of Spain under two scenarios (A2 and B1) and for three periods (2005 to 2009, 2041 to 2060, and 2081 to 2100). Simulations showed that the level of risk predicted by BSPcast model increased to high or very high under the two scenarios and was differentially distributed in the two regions. This study is an example of how epidemiological models can be used to predict not only the onset of infections but also how climate change could affect brown spot of pear.
\end{abstract}

Stemphylium vesicarium (Wallr.) E.G. Simmons (teleomorph Pleospora allii) is the causal agent of brown spot of pear (Pyrus communis L.), an important disease with a similar or even higher incidence than apple scab in some pear-growing areas in Europe (Llorente and Montesinos 2006a). The disease has been reported in Spain, Italy, France, The Netherlands, Belgium, and Portugal (Llorente and Montesinos 2006a). Symptoms consist of necrotic lesions on leaves, twigs, and fruit, and the fruit can also rot and become unmarketable (Llorente and Montesinos 2006a; Rossi et al. 2007). The first symptoms appear at the end of April on leaves and from May to June on fruit (Llorente et al. 2010) and infections can occur over the whole season. The disease cycle is characterized by two phases; a pathogenic phase on the aerial pear organs during the growing season, and a saprophytic phase on plant debris on the orchard ground during the year (Llorente et al. 2011 b). In the past 20 years, several aspects related to the epidemiology and inoculum production of brown spot of pear (BSP) have been elucidated, different forecasting models have been developed for use in warning systems, and new strategies of control have been proposed for disease management (Llorente and Montesinos 2006a; Llorente et al. 2011b).

A weather-based forecasting model, BSPcast (Brown Spot of Pear forecasting system), was developed under controlled-environment conditions to predict $S$. vesicarium infections in pear (Montesinos et al. 1995b). Within BSPcast, a polynomial equation describes the

†Corresponding author: I. Llorente; E-mail: isidre.llorente@udg.edu effect of temperature $(T)$ and duration of wetness $(W)$ on disease severity $(S)$ as follows:

$$
\begin{aligned}
\log _{10}(S)= & -1.70962+0.0289 T+0.04943 W \\
& +0.00868 T W-0.002362 W^{2}-0.000238 T^{2} W
\end{aligned}
$$

Since the maximum daily disease severity (lesions/leaf) predicted by the equation is 3.79 , a relative daily infection risk $(R)$ ranges from 0 to 1 . For field applications, the BSPcast model uses weather variables from daily periods $(24 \mathrm{~h})$ from 8:00 GMT of the previous day to 8:00 GMT of the current day. Thus, $R$ values and 3 -day cumulative daily infection risk (CR) obtained by summing $R$ values for the past 3 days are calculated every $24 \mathrm{~h}$. Values of $R$ and $\mathrm{CR}$ are used as an indication of disease risk. This risk model was evaluated and validated for predicting $S$. vesicarium infection risk under a wide range of orchard and climatic conditions in different areas of Europe (Llorente et al. 2000). Currently, BSPcast is implemented as a warning system in Catalonia (Spain) and EmiliaRomagna (Italy) and has also been used as a warning system for reducing fungicide use in disease management programs in Belgium, The Netherlands, and Portugal (Llorente and Montesinos 2006a; Llorente et al. 2011b). The BSPcast has resulted in 30 to $40 \%$ savings in fungicide applications compared with standard calendarbased applications, but with a comparable level of disease control (Llorente et al. 2011b). The effect of interrupted wetness periods, relative humidity during the interrupted wetness period, and high relative humidity without wetness on disease progress was determined later and included in the BSPcast model (Llorente and Montesinos 2002; Llorente et al. 2011a).

The PAMcast model (Pleospora allii Maturation forecast) was developed to predict the percentage of mature pseudothecia of 
$P$. allii based on temperature and relative humidity in winter. The model quantifies the effect of cumulative degree days in the maturation process of pseudothecia and has been evaluated and validated under field conditions over several years (Llorente and Montesinos 2004) this model can be used for guiding control measures to reduce overwintering inoculum.

The proposed integrated management of BSP includes sanitation methods aimed to decrease inoculum potential. These methods consist of leaf litter removal from December to February and application of biological control agents based on Trichoderma spp. to the orchard grounds from February to May supported by the PAMcast model for determining the evolution of overwintering inoculum. Additionally, the control of $S$. vesicarium infections is based on fungicide sprays on trees during pear-growing season, scheduled according to the BSPcast model. These methods have been tested separately or in combination over several years (Llorente

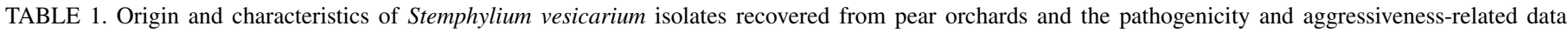
obtained from inoculation tests on cultivar Conference detached leaves

\begin{tabular}{|c|c|c|c|c|c|c|c|c|c|}
\hline \multirow[b]{2}{*}{ Isolate ID } & \multicolumn{3}{|c|}{ Origin } & \multicolumn{6}{|c|}{ Pathogenicity and aggressiveness ${ }^{\mathrm{a}}$} \\
\hline & Country $^{b}$ & Cultivar ${ }^{\mathrm{c}}$ & Source & Incidence & Severity (Sf) & AUDPC & Model & Pathogenic & Aggressiveness \\
\hline EPS2 & Spain $(6 ; 5)$ & Passe Crassane & Lesion fruit & 83.33 & 76.39 & 347.24 & M & + & 3 \\
\hline EPS8 & Spain $(6 ; 12)$ & Passe Crassane & Lesion fruit & 100.00 & 100.00 & 550.00 & M & + & 3 \\
\hline EPS11 & Spain $(6 ; 13)$ & Passe Crassane & Lesion fruit & 100.00 & 98.61 & 587.24 & M & + & 3 \\
\hline EPS14 & Spain $(6 ; 7)$ & Passe Crassane & Lesion fruit & 100.00 & 83.33 & 385.42 & M & + & 3 \\
\hline EPS15 & Spain $6 ; 14)$ & Conference & Lesion fruit & 100.00 & 75.00 & 304.86 & M & + & 2 \\
\hline EPS19 & Spain $(6 ; 4)$ & Conference & Lesion fruit & 100.00 & 62.50 & 304.16 & M & + & 2 \\
\hline EPS20 & Spain $(6 ; 7)$ & Passe Crassane & Lesion fruit & 100.00 & 85.41 & 377.77 & M & + & 3 \\
\hline EPS21 & Spain $(6 ; 15)$ & Passe Crassane & Lesion fruit & 100.00 & 81.94 & 387.50 & M & + & 3 \\
\hline EPS26 & Spain $(6 ; 5)$ & Passe Crassane & Lesion fruit & 100.00 & 87.35 & 371.97 & M & + & 3 \\
\hline EPS27 & Spain $(6 ; 5)$ & Passe Crassane & Lesion fruit & 94.44 & 81.94 & 421.53 & M & + & 3 \\
\hline EPS28 & Spain $(6 ; 5)$ & Passe Crassane & Lesion fruit & 100.00 & 76.39 & 318.55 & M & + & 3 \\
\hline EPS29 & Spain $(6 ; 5)$ & Passe Crassane & Lesion fruit & 100.00 & 75.00 & 272.92 & M & + & 2 \\
\hline EPS31 & Spain $(7 ; 1)$ & Passe Crassane & Lesion leaf & 100.00 & 100.00 & 550.00 & M & + & 3 \\
\hline EPS32 & Spain $(11 ; 6)$ & Conference & Leaf debris & 38.89 & 25.00 & 205.56 & M & + & 1 \\
\hline EPS33 & Spain $(11 ; 6)$ & Conference & Leaf debris & 83.33 & 33.33 & 208.33 & $\mathrm{~L}$ & + & 1 \\
\hline EPS34 & Spain $(11 ; 6)$ & Conference & Leaf debris & 83.33 & 31.25 & 203.33 & $\mathrm{~L}$ & + & 1 \\
\hline EPS35 & Spain $(7 ; 1)$ & Conference & Lesion fruit & 100.00 & 100.00 & 550.00 & M & + & 3 \\
\hline EPS36 & Spain $(7 ; 16)$ & Conference & Lesion fruit & 100.00 & 100.00 & 550.00 & M & + & 3 \\
\hline EPS37 & Portugal $(5 ; 17)$ & Rocha & Lesion leaf & 100.00 & 77.78 & 370.13 & M & + & 3 \\
\hline EPS38 & Portugal $(11 ; 17)$ & Rocha & Lesion leaf & 100.00 & 100.00 & 550.00 & M & + & 3 \\
\hline EPS41 & Spain $(5 ; 2)$ & Conference & Air & 55.56 & 36.11 & 182.15 & $\mathrm{~L}$ & + & 1 \\
\hline EPS42 & Spain $(5 ; 2)$ & Conference & Air & 27.78 & 30.56 & 138.89 & $\mathrm{M}$ & + & 1 \\
\hline EPS43 & Spain $(5 ; 2)$ & Conference & Air & 18.33 & 5.56 & 24.44 & $\mathrm{np}$ & - & 0 \\
\hline EPS44 & Spain $(5 ; 2)$ & Conference & Air & 14.26 & 7.74 & 89.58 & np & - & 0 \\
\hline EPS45 & Spain $(5 ; 2)$ & Conference & Air & 5.56 & 2.78 & 13.89 & np & - & 0 \\
\hline EPS46 & Spain $(5 ; 2)$ & Conference & Air & 4.23 & 1.39 & 8.33 & $\mathrm{np}$ & - & 0 \\
\hline EPS50 & Spain $(11 ; 19)$ & Conference & Air & 0.00 & 0.00 & 0.00 & $\mathrm{np}$ & - & 0 \\
\hline EPS52 & Spain $(5 ; 1)$ & Conference & Leaf debris & 38.89 & 20.83 & 115.97 & M & + & 1 \\
\hline EPS53 & Spain $(5 ; 1)$ & Passe Crassane & Air & 11.00 & 6.11 & 81.67 & $\mathrm{np}$ & - & 0 \\
\hline EPS54 & Spain $(5 ; 1)$ & Passe Crassane & Air & 27.78 & 22.22 & 120.01 & $\mathbf{M}$ & + & 1 \\
\hline EPS57 & Spain $(5 ; 1)$ & Passe Crassane & Lesion leaf & 100.00 & 88.89 & 272.91 & $\mathrm{~L}$ & + & 3 \\
\hline EPS58 & Spain $(5 ; 1)$ & Passe Crassane & Lesion leaf & 100.00 & 100.00 & 501.32 & $\mathrm{~L}$ & + & 3 \\
\hline EPS59 & Spain $(6 ; 3)$ & Passe Crassane & Lesion leaf & 100.00 & 86.67 & 234.03 & $\mathrm{~L}$ & + & 3 \\
\hline EPS60 & Spain $(5 ; 3)$ & Passe Crassane & Lesion leaf & 100.00 & 100.00 & 489.24 & $\mathrm{~L}$ & + & 3 \\
\hline EPS61 & Spain $(11 ; 20)$ & Passe Crassane & Leaf debris & 100.00 & 94.44 & 385.42 & $\mathrm{~L}$ & + & 3 \\
\hline EPS62 & Spain $(11 ; 8)$ & Conference & Leaf debris & 100.00 & 87.50 & 200.69 & $\mathrm{~L}$ & + & 3 \\
\hline EPS63 & Spain $(11 ; 11)$ & Conference & Leaf debris & 77.78 & 17.78 & 144.36 & M & + & 1 \\
\hline EPS64 & Spain $(11 ; 9)$ & Conference & Lesion leaf & 100.00 & 94.44 & 265.97 & $\mathrm{~L}$ & + & 3 \\
\hline EPS66 & Spain $(11 ; 1)$ & Passe Crassane & Lesion leaf & 44.44 & 29.17 & 105.56 & $\mathrm{M}$ & + & 1 \\
\hline EPS67 & Spain $(5 ; 3)$ & Passe Crassane & Lesion leaf & 17.40 & 5.56 & 33.34 & $\mathrm{np}$ & - & 0 \\
\hline EPS68 & Spain $(11 ; 11)$ & Conference & Leaf debris & 14.82 & 9.51 & 54.86 & $\mathrm{np}$ & - & 0 \\
\hline EPS69 & Spain $(5 ; 3)$ & Passe Crassane & Lesion leaf & 100.00 & 100.00 & 550.00 & M & + & 3 \\
\hline EPS73 & Spain $(5 ; 3)$ & Passe Crassane & Lesion leaf & 100.00 & 100.00 & 550.00 & M & + & 3 \\
\hline EPS74 & Spain $(11 ; 21)$ & Conference & Leaf debris & 5.56 & 4.17 & 33.33 & $\mathrm{np}$ & - & 0 \\
\hline EPS75 & Spain $(11 ; 8)$ & Conference & Leaf debris & 77.78 & 51.39 & 302.78 & $\mathrm{~L}$ & + & 2 \\
\hline EPS76 & Spain $(11 ; 22)$ & Conference & Leaf debris & 100.00 & 79.17 & 397.54 & $\mathrm{~L}$ & + & 3 \\
\hline EPS77 & Spain $(5 ; 3)$ & Passe Crassane & Lesion leaf & 50.00 & 34.72 & 193.33 & $\mathrm{M}$ & + & 1 \\
\hline EPS78 & Spain $(11 ; 23)$ & Conference & Leaf debris & 0.00 & 0.00 & 0.00 & $\mathrm{np}$ & - & 0 \\
\hline EPS80 & Spain $(11 ; 24)$ & Conference & Lesion leaf & 5.56 & 9.72 & 94.45 & np & - & 0 \\
\hline EPS81 & Spain $(11 ; 8)$ & Conference & Lesion leaf & 100.00 & 94.44 & 547.21 & $\mathrm{M}$ & + & 3 \\
\hline EPS82 & Spain $(6 ; 4)$ & Conference & Lesion leaf & 100.00 & 100.00 & 550.00 & M & + & 3 \\
\hline
\end{tabular}

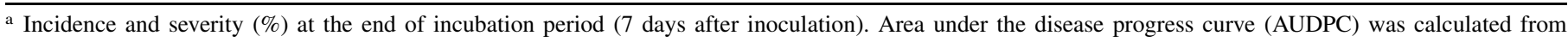
disease severity data at $0,3,5$, and 7 days after $S$. vesicarium inoculation. Values are the mean of three independent experiments and three replicates of three inoculated cultivar Conference pear leaves per experiment. Model: disease progress curve best fit model for pathogenic isolates (M, monomolecular; L, logistic; and $\mathrm{np}$, no model was assigned to nonpathogenic isolates). Pat: pathogenicity on Conference detached leaves (-, nonpathogenic (Sf $\leq 10 \%)$; and + , pathogenic $(\mathrm{Sf}>10 \%)$ ). Aggressiveness level defined according to Sf values $(0=\mathrm{Sf} \leq 10 \% ; 1=10<\mathrm{Sf} \leq 40 ;$ and $2=40<\mathrm{Sf} \leq 75 ; 3=\mathrm{Sf}>75 \%)$.

b First number in parentheses corresponds to the month of isolation and the second one refers to the orchard identification code.

c nd: not defined.

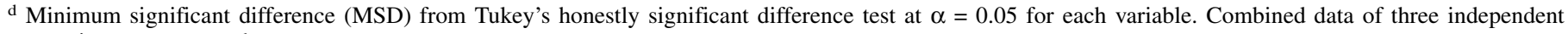
experiments were used. 
et al. 2006b, 2010, 2011b). Treatments with fungicides applied alone or combined with sanitation methods are the most effective, with a reduction of disease incidence in fruit higher than $60 \%$ compared with the nontreated control. Sanitation methods applied alone reduced the disease incidence by 30 to $60 \%$. These results demonstrated the importance of inoculum in the management of BSP.

Some aspects of $S$. vesicarium inoculum are, however, still unclear and especially those concerning its pathogenic and saprophytic behavior. The genus Stemphylium has been described as saprophytic with species in this genus being colonizers of dead plant tissues (Hudson 1971). S. vesicarium and P. allii are able to colonize pear leaf debris and necrotic tissues of herb plants on the ground, where they produce abundant ascospores and conidia that are capable of infecting pear trees (Llorente et al. 2006b; Rossi et al. 2005b). Potential inoculum sources include lesions on host tissues caused by pathogenic isolates, host debris, and nonhost dead tissues

TABLE 1. (Continued from previous page)

\begin{tabular}{|c|c|c|c|c|c|c|c|c|c|}
\hline \multirow[b]{2}{*}{ Isolate ID } & \multicolumn{3}{|c|}{ Origin } & \multicolumn{6}{|c|}{ Pathogenicity and aggressiveness ${ }^{\mathrm{a}}$} \\
\hline & Country $^{b}$ & Cultivar $^{\mathrm{c}}$ & Source & Incidence & Severity (Sf) & AUDPC & Model & Pathogenic & Aggressiveness \\
\hline EPS83 & Spain $(6 ; 4)$ & Conference & Lesion leaf & 100.00 & 98.61 & 514.96 & M & + & 3 \\
\hline EPS84 & Spain $(6 ; 4)$ & Conference & Lesion leaf & 100.00 & 95.83 & 479.17 & M & + & 3 \\
\hline EPS85 & Spain $(5 ; 3)$ & Passe Crassane & Lesion leaf & 100.00 & 100.00 & 550.00 & M & + & 3 \\
\hline EPS86 & Spain $(5 ; 3)$ & Passe Crassane & Lesion leaf & 100.00 & 100.00 & 550.00 & M & + & 3 \\
\hline EPS87 & Spain $(5 ; 3)$ & Passe Crassane & Lesion leaf & 100.00 & 97.22 & 393.75 & M & + & 3 \\
\hline EPS88 & Spain $(11 ; 10)$ & Conference & Leaf debris & 100.00 & 95.83 & 548.81 & $\mathrm{~L}$ & + & 3 \\
\hline EPS89 & Spain $(11 ; 10)$ & Abate Fetel & Leaf debris & 100.00 & 100.00 & 502.02 & $\mathrm{~L}$ & + & 3 \\
\hline EPS90 & Spain $(5 ; 1)$ & Passe Crassane & Lesion leaf & 100.00 & 100.00 & 550.00 & M & + & 3 \\
\hline EPS91 & Spain $(11 ; 9)$ & Passe Crassane & Leaf debris & 100.00 & 100.00 & 550.00 & M & + & 3 \\
\hline EPS92 & Spain $(11 ; 9)$ & Passe Crassane & Leaf debris & 100.00 & 100.00 & 550.00 & M & + & 3 \\
\hline EPS95 & Spain $(11 ; 11)$ & Conference & Leaf debris & 50.00 & 38.89 & 297.22 & M & + & 1 \\
\hline EPS96 & Spain $(11 ; 25)$ & Conference & Leaf debris & 0.00 & 0.00 & 0.00 & $\mathrm{np}$ & - & 0 \\
\hline EPS97 & Spain $(5 ; 3)$ & Passe Crassane & Lesion leaf & 100.00 & 100.00 & 550.00 & $\mathrm{M}$ & + & 3 \\
\hline EPS98 & Spain $(5 ; 3)$ & Passe Crassane & Lesion leaf & 100.00 & 100.00 & 550.00 & M & + & 3 \\
\hline EPS104 & Spain $(11 ; 4)$ & General Leclerc & Leaf debris & 33.33 & 29.17 & 238.89 & M & + & 1 \\
\hline EPS105 & Spain $(11 ; 9)$ & Passe Crassane & Leaf debris & 55.56 & 43.06 & 305.00 & $\mathrm{~L}$ & + & 2 \\
\hline EPS106 & Spain $(11 ; 26)$ & Passe Crassane & Leaf debris & 88.89 & 61.11 & 384.28 & $\mathrm{~L}$ & + & 2 \\
\hline EPS107 & Spain $(8 ; 1)$ & Passe Crassane & Air & 0.00 & 0.00 & 0.00 & $\mathrm{np}$ & - & 0 \\
\hline EPS110 & Spain $(6 ; 1)$ & Passe Crassane & Air & 96.30 & 80.56 & 249.53 & $\mathrm{~L}$ & + & 3 \\
\hline EPS111 & Spain $(6 ; 1)$ & Passe Crassane & Air & 0.00 & 0.00 & 0.00 & $\mathrm{np}$ & - & 0 \\
\hline EPS112 & Spain $(6 ; 1)$ & Passe Crassane & Air & 3.70 & 3.70 & 9.26 & $\mathrm{np}$ & - & 0 \\
\hline EPS113 & Spain $(6 ; 1)$ & Passe Crassane & Air & 3.70 & 2.78 & 8.80 & $\mathrm{np}$ & - & 0 \\
\hline EPS114 & Spain $(6 ; 1)$ & Passe Crassane & Air & 7.41 & 6.48 & 26.85 & $\mathrm{np}$ & - & 0 \\
\hline EPS115 & Spain $(6 ; 1)$ & Passe Crassane & Air & 14.82 & 9.26 & 26.85 & $\mathrm{np}$ & - & 0 \\
\hline EPS116 & Spain $(6 ; 1)$ & Passe Crassane & Air & 7.41 & 5.56 & 23.61 & $\mathrm{np}$ & - & 0 \\
\hline EPS119 & Spain $(8 ; 23)$ & Conference & Lesion fruit & 100.00 & 100.00 & 500.00 & $\mathrm{~L}$ & + & 3 \\
\hline EPS122 & Spain $(7 ; 3)$ & Passe Crassane & Air & 29.63 & 23.15 & 73.84 & $\mathrm{~L}$ & + & 1 \\
\hline EPS123 & Spain $(7 ; 3)$ & Passe Crassane & Air & 3.70 & 1.85 & 3.70 & $\mathrm{np}$ & - & 0 \\
\hline EPS124 & Spain $(7 ; 3)$ & Passe Crassane & Air & 3.70 & 3.70 & 13.42 & $\mathrm{np}$ & - & 0 \\
\hline EPS126 & Spain $(7 ; 3)$ & Passe Crassane & Air & 14.82 & 9.96 & 52.77 & $\mathrm{np}$ & - & 0 \\
\hline EPS127 & Spain $(7 ; 3)$ & Passe Crassane & Air & 0.00 & 0.00 & 0.00 & $\mathrm{np}$ & - & 0 \\
\hline EPS130 & Spain $(6 ; 1)$ & Passe Crassane & Air & 3.70 & 3.70 & 18.06 & $\mathrm{np}$ & - & 0 \\
\hline EPS131 & Spain $(7 ; 3)$ & Passe Crassane & Air & 0.00 & 0.00 & 0.00 & $\mathrm{np}$ & - & 0 \\
\hline EPS133 & Spain $(7 ; 3)$ & Passe Crassane & Air & 3.70 & 3.70 & 18.52 & $\mathrm{np}$ & - & 0 \\
\hline EPS134 & Spain $(7 ; 3)$ & Passe Crassane & Air & 0.00 & 0.00 & 0.00 & $\mathrm{np}$ & - & 0 \\
\hline EPS135 & Spain $(7 ; 3)$ & Passe Crassane & Air & 0.00 & 0.00 & 0.00 & $\mathrm{np}$ & - & 0 \\
\hline EPS136 & Spain $(7 ; 3)$ & Passe Crassane & Air & 3.70 & 2.78 & 15.74 & $\mathrm{np}$ & - & 0 \\
\hline EPS137 & Spain $(7 ; 3)$ & Passe Crassane & Air & 0.00 & 0.00 & 0.00 & $\mathrm{np}$ & - & 0 \\
\hline EPS138 & Spain $(7 ; 3)$ & Passe Crassane & Air & 0.00 & 0.00 & 0.00 & $\mathrm{np}$ & - & 0 \\
\hline EPS139 & Spain $(7 ; 3)$ & Passe Crassane & Air & 0.00 & 0.00 & 0.00 & $\mathrm{np}$ & - & 0 \\
\hline EPS141 & Spain $(7 ; 3)$ & Passe Crassane & Air & 3.70 & 3.70 & 9.26 & $\mathrm{np}$ & - & 0 \\
\hline EPS142 & Spain $(7 ; 3)$ & Passe Crassane & Air & 22.22 & 9.00 & 50.93 & $\mathrm{np}$ & - & 0 \\
\hline EPS144 & Spain $(7 ; 3)$ & Passe Crassane & Air & 0.00 & 0.00 & 0.00 & $\mathrm{np}$ & - & 0 \\
\hline EPS145 & Spain $(7 ; 4)$ & General Leclerc & Air & 3.70 & 5.56 & 17.13 & $\mathrm{np}$ & - & 0 \\
\hline EPS147 & Spain $(7 ; 3)$ & Passe Crassane & Air & 0.00 & 0.00 & 0.00 & $\mathrm{np}$ & - & 0 \\
\hline EPS148 & Spain $(7 ; 3)$ & Passe Crassane & Air & 3.70 & 3.70 & 7.41 & $\mathrm{np}$ & - & 0 \\
\hline EPS149 & Spain $(7 ; 3)$ & Passe Crassane & Air & 0.00 & 0.00 & 0.00 & $\mathrm{np}$ & - & 0 \\
\hline EPS151 & Spain $(7 ; 1)$ & Passe Crassane & Air & 0.00 & 0.00 & 0.00 & $\mathrm{np}$ & - & 0 \\
\hline EPS152 & Spain $(7 ; 3)$ & Passe Crassane & Air & 0.00 & 0.00 & 0.00 & $\mathrm{np}$ & - & 0 \\
\hline EPS 153 & Spain $(7 ; 3)$ & Passe Crassane & Air & 0.00 & 0.00 & 0.00 & $\mathrm{np}$ & - & 0 \\
\hline EPS154 & Spain $(7 ; 4)$ & General Leclerc & Air & 0.00 & 0.00 & 0.00 & $\mathrm{np}$ & - & 0 \\
\hline EPS156 & Spain $(7 ; 4)$ & General Leclerc & Air & 0.00 & 0.00 & 0.00 & $\mathrm{np}$ & - & 0 \\
\hline EPS157 & Spain $(11 ; 1)$ & weed & Lesion leaf & 100.00 & 74.07 & 319.91 & $\mathrm{M}$ & + & 2 \\
\hline EPS158 & Spain $(6 ; 1)$ & Passe Crassane & Air & 0.00 & 0.00 & 0.00 & $\mathrm{np}$ & - & 0 \\
\hline PRI 850 & Netherlands $(6 ; 27)$ & Conference & Lesion fruit & 100.00 & 98.15 & 480.55 & M & + & 3 \\
\hline PRI 869 & Netherlands $(11 ; 27)$ & Conference & Leaf debris & 100.00 & 75.00 & 325.00 & $\mathrm{~L}$ & + & 2 \\
\hline PRI 890 & Netherlands $(11 ; 27)$ & D. Comice & Leaf debris & 100.00 & 100.00 & 550.00 & M & + & 3 \\
\hline F39_06 & France $(11 ; 18)$ & nd & Lesion & 100.00 & 95.83 & 316.67 & $\mathrm{~L}$ & + & 3 \\
\hline \multicolumn{4}{|c|}{ Mean standard error } & 7.36 & 6.09 & 23.09 & & & \\
\hline \multicolumn{4}{|c|}{ Mean } & 53.55 & 46.37 & 230.55 & & & \\
\hline \multicolumn{4}{|l|}{$\operatorname{MSD}^{\mathrm{d}}$} & 26.09 & 29.54 & 193.14 & & & \\
\hline
\end{tabular}


colonized by pathogenic or saprophytic isolates (Köhl et al. 2008, 2009; Pattori et al. 2006). S. vesicarium conidia are airborne throughout the growing season and inoculum in orchards is composed of spores released from all the different inoculum sources. The proportion of pathogenic and nonpathogenic inoculum and its aggressiveness in populations of $S$. vesicarium that compose the different inoculum sources in pear orchards remain unknown.

Climate change is another major factor that can produce variations in the severity and geographical distribution of brown spot of pear. Changes associated with global warming (i.e., increased temperatures, changes in the quantity and pattern of precipitation) are expected to affect pathogen development, resulting in changes in the impact of diseases on crops (Coakley et al. 1999; Elad and Pertot 2014). The effects of climate change will differ by pathosystem and geographical region. Knowledge on the dynamics of BSP provided by BSPcast and complementary epidemiological information may be used to simulate changes in crop loss and the geographical distribution of the disease. Future greenhouse gas emissions are the result of very complex dynamic systems determined by driving forces such as demographic and socio-economic development and technological change (Nakićenović et al. 2000). The evolution of climate change is highly uncertain, and different scenarios have been developed. Four scenarios have been described (A1, A2, B1, and B2) as a function of different greenhouse gas emissions and may be used to make projections for possible future climate change (Nakićenović et al. 2000). The A2 scenario describes a very heterogeneous world with continuously increasing global population. Economic development is primarily regionally oriented. The B1 scenario describes a convergent world with the same global population that peaks in midcentury and declines thereafter, with reductions in material intensity and the introduction of clean and resource-efficient technologies. The emphasis is on global solutions to economic, social, and environmental sustainability. The A2 is a severe scenario, whereas the B1 is a moderate scenario. Under these scenarios, knowledge on how the impact of climate change in different regions can modify the trends in BSP in relation to crop losses, and how this modification can affect disease management is of great interest.

The aims of this study were twofold: (i) to characterize $S$. vesicarium populations in pear orchards according to their pathogenicity and aggressiveness and to establish their relationship with sources of inoculum using a multivariate analysis and (ii) to determine the evolution of brown spot of pear infection risk under scenarios A2 and B1 of climate change during 2041 to 2060 and 2081 to 2100 time periods using the BSPcast model.

\section{MATERIALS AND METHODS}

Sample collection and isolation of $S$. vesicarium. A total of 27 pear orchards distributed across a $1,360 \mathrm{~km}^{2}$ area in Catalonia (Northeast of Spain) growing different pear cultivars (Abate Fetel, Conference, Doyenne du Comice, and General Leclerc) affected by BSP were selected for $S$. vesicarium sampling (Table 1). Isolates were collected from different sources including leaf and fruit lesions, lesions in herbaceous plants growing between the pear tree rows (weeds), air samples, and pseudothecia on leaf debris on the orchard ground during a 3-year period (2007 to 2009). Infected leaves and fruit were collected in the summer, air samples were captured in the spring and summer, and leaf debris were recovered from the orchard ground in the autumn. Pear fruit and leaves showing lesions of BSP and infected leaves of weeds growing in the orchard were collected from each field, placed in plastic bags in ice coolers and carried to the laboratory for isolation. Infected leaves and fruit were surface disinfected by immersion for 1 to $2 \mathrm{~min}$ in a $1 \%$ sodium hypochlorite solution, rinsed three times in sterile distilled water, and dried in a flow cabinet on sterile filter paper. One or two pieces of necrotic tissue ( 3 to $5 \mathrm{~mm}$ ) from the edge of a lesion were cut and placed on tomato agar plates $(800 \mathrm{ml}$ of distilled water, $10 \mathrm{~g}$ of concentrated tomato, $2.3 \mathrm{~g}$ of $\mathrm{CaCO}_{3}$, and $12.8 \mathrm{~g}$ of agar).
Plates were incubated at $25^{\circ} \mathrm{C}$ under a 16-h-light photoperiod for 5 days. Pure cultures of colonies with morphology resembling that of Stemphylium were obtained after transfer to tomato agar plates and incubation for 7 days under the previous conditions. Pear leaf debris with brown spot lesions were collected from the orchard ground and transferred to a climatic growth chamber at $10^{\circ} \mathrm{C}$ for pseudothecia development and asci maturation. After 3 to 5 months, mature pseudothecia were isolated from leaf tissues, placed on tomato agar plates, and incubated at $25^{\circ} \mathrm{C}$ as described above. Pure cultures of colonies with a morphology resembling that of Stemphylium were obtained as described above after incubation for 7 days. Air samples were taken with an air sampler (Sampl'air, AES CHEMUNEX, Bruz, France) placed between the pear tree rows, $50 \mathrm{~cm}$ from trees and $1 \mathrm{~m}$ above the ground, in 40 randomly distributed locations in the orchard. A 50-liter air volume was aspirated each time by the suction system to directly trap air spores on tomato agar $90 \mathrm{~mm}$ Petri dishes. Plates were incubated for 5 days at $25^{\circ} \mathrm{C}$ under a 16-h light photoperiod and colonies with morphology resembling Stemphylium were transferred to tomato agar plates for pure culture production. All isolates were purified by single-spore isolation and maintained on tomato agar slants at $4{ }^{\circ} \mathrm{C}$ as stock cultures.

Assignment of isolates to Stemphylium species was made based on culture morphology, conidia morphology and size, and internal transcribed spacer and gpd partial gene sequences (Puig et al. 2015b). Characterized isolates were deposited in the Culture Collection of Institute of Food and Agricultural Technology of the University of Girona (INTEA, Girona, Spain). Only isolates identified as $S$. vesicarium were subsequently used and a total of 104 isolates from different pear orchards in northeastern Spain were analyzed in this study. Six additional isolates recovered in orchards from The Netherlands (three isolates, provided by J. Köhl, Plant Research International, The Netherlands), France (one isolate, provided by M. Giraud, Centre Ctifl de Lanxade, France), and Portugal (two isolates, obtained in this study) were also included. Forty-four percent of isolates analyzed were recovered from air samples, $23 \%$ from pseudothecia on leaf debris, and $42 \%$ from lesions (16\% on pear fruit and $26 \%$ on pear leaves, and $1 \%$ on weed leaves) (Table 1).

Plant material. Pear plants of self-rooted cultivar Conference (CAV clone) obtained by micropropagation (Agromillora Catalana S.A., Barcelona, Spain) were used to determine the pathogenicity and aggressiveness of collected isolates. Plants were 2 to 3 years old, approximately $30 \mathrm{~cm}$ high, and grown in 1-liter plastic containers filled with a commercial peat moss/vermiculite/perlite potting mix (type BVU, Prodeasa, Girona, Spain). Plants were chilled in winter, pruned, and forced to bud in the greenhouse 2 to 3 months before the experiments were initiated. Actively growing plants were maintained in the greenhouse and fertilized once a week with a solution of 200 ppm N-P-K (20-10-20). Plants were used in three independent experiments performed in spring-summer of two consecutive years.

Inoculation and disease development. The pathogenicity and aggressiveness of $110 \mathrm{~S}$. vesicarium isolates (Table 1) were evaluated using a detached leaf assay (Puig et al. 2014; 2015b). Working cultures of isolates were grown on tomato agar at $22.5^{\circ} \mathrm{C}$ under a 16-h light photoperiod in a growth cabinet (I-30BLL Percival Plant Biology Chamber, Percival Scientific Inc.). Conidial suspensions were obtained from 10-day-old cultures by flooding the plate with $10 \mathrm{ml}$ of sterile distilled water with a drop of Tween 20 and gently rubbing the colony surface with a sterile Digralsky spreader. The suspension was filtered through $0.2 \mathrm{~mm}$ mesh sieves to separate mycelium from conidia and maintained at $4{ }^{\circ} \mathrm{C}$ to prevent germination during manipulation. Conidial concentration was determined with a hemocytometer and adjusted to 2 to $3 \times 10^{5}$ conidia/ $\mathrm{ml}$. Inoculations were performed on detached leaves of actively growing cultivar Conference pear plants. Only young leaves corresponding to the newly formed leaves in a tip were used. Leaves were dipped in a solution of $1 \%$ sodium hypochlorite for $5 \mathrm{~min}$, rinsed three times in sterile distilled water, and excess water was removed with a 
filter paper. Leaves were then placed with the reverse side up on sterile moistened filter paper in plastic $\left(40 \times 80 \mathrm{~cm}^{2}\right)$ dishes and inoculated by depositing two $30 \mu \mathrm{l}$ of conidial suspension on the leaf surface, one at each side of the midrib. Each isolate was inoculated individually on a leaf. Control leaves were inoculated with sterile distilled water. Plastic dishes with inoculated leaves were sealed into moistened transparent plastic bags and incubated for 7 days at $25^{\circ} \mathrm{C}$ under a 16-h-light photoperiod in a controlled-environment chamber (MLR-350 Growth Cabinet, SANYO, Japan). A completely random design was used with three replicates of three leaves per replicate. The replicates of each isolate were randomly distributed in different dishes. The experiment was conducted three times.

Disease assessment. Disease incidence (percentage of inoculation sites that developed brown spot lesions) and disease severity (necrosis size) were evaluated $0,3,5$, and 7 days after inoculation. Disease severity was assessed for each inoculation according to the severity index (I): $0=$ no infection, $1=0<$ necrosis $<$ $2.5 \mathrm{~mm}, 2=2.5 \mathrm{~mm} \leq$ necrosis $<5 \mathrm{~mm}, 3=5 \mathrm{~mm} \leq$ necrosis $<10 \mathrm{~mm}$, and $4=$ necrosis $\geq 10 \mathrm{~mm}$ (Puig et al. 2014). The disease severity per replicate $(\mathrm{S})$ was then calculated according to the following formula:

$$
S=\frac{\sum_{n=1}^{N} I_{n}}{N \times 4} \times 100
$$

where $I_{n}$ is the corresponding severity index for each inoculation and $N$ is the number of inoculations per replicate (Puig et al. 2014).

Pathogenicity and aggressiveness of $S$. vesicarium isolates. Isolates were considered pathogenic when able to infect pear leaves and develop progressive lesions. Small necrotic spots restricted to the inoculation site were attributed to the $S$. vesicarium toxin effects produced by pathogenic and nonpathogenic isolates when inoculated on host organs (Singh et al. 1999). The effect of isolate on final disease incidence and severity was evaluated using analysis of variance after confirmation of normality and homoscedasticity using the PROC GLM of SAS (version 9.2; SAS Institute Inc., Cary, NC). The effect of experiment on disease incidence and severity was also evaluated in the same analysis. Differences between isolates in final disease incidence and severity were tested using the Tukey's honestly significant difference (HSD) test $(\alpha=0.05)$. Based on the mean final disease severity (Sf) assessed 7 days after inoculation, and the means separation test results, isolates were classified into four aggressiveness groups: $0=\mathrm{Sf} \leq 10 \%, 1=10<\mathrm{Sf} \leq 40,2=40<$ $\mathrm{Sf} \leq 75$, and $3=\mathrm{Sf}>75 \%$. Group 0 represented nonpathogenic isolates and included isolates that did not induce necrosis and isolates that produced small necrotic spots restricted to the inoculation point (in all cases Sf was up to $10 \%$ ).

Disease progress over time. A more detailed study of isolate aggressiveness was performed by analyzing disease development over time. The progress curves of disease severity versus time were plotted for each isolate replicate and experiment, and the area under disease progress curve (AUDPC) was calculated (Campbell and Madden 1990). The effect of isolate and experiment on AUDPC was analyzed using PROC GLM as described above. Additionally, the disease progress data were fitted to growth models to characterize the pattern of disease development for each isolate. Disease severity (y) was regressed with time based on the Gompertz $[Y=-\ln (-\ln (y))]$, logistic $[Y=\ln (y / 1-y)]$, monomolecular $[Y=\ln (1 /(1-y))]$, and logarithmic $[Y=\ln (y)]$ transformations and analyzed using the REG procedure of SAS. The coefficient of determination, the standard error and significance of the slope parameter, the mean square errors, and the patterns of residuals versus predicted values were used to evaluate the goodness-of-fit of the models to data. The best model for each isolate was selected based on the lowest mean square error and the recalculated $R^{2}$ (Campbell and Madden 1990; Neter et al. 1985). Only disease progress curves of pathogenic isolates were modeled.

Relationship between isolate origin, pathogenicity, and aggressiveness. Principal component analysis (PCA) was performed to evaluate the relationship between pathogenicity, aggressiveness and the origin of 110 S. vesicarium isolates (Table 1) using the PRINCOMP procedure of SAS. Ten variables were included in the analysis, four of which related to the origin of isolates (orchard, pear cultivar, source of isolation, and month of isolation) and six variables related to pathogenicity and aggressiveness (final incidence, final severity, AUDPC, disease progress curve model, pathogenicity, and aggressiveness) (Table 1). Average data from all experiments were used in PCA analysis.

Determination of the evolution of brown spot of pear infection risk under scenarios A2 and B1 of climate change. Two scenarios were selected from the Special Report on Emission Scenarios (SRES) (Nakićenović et al. 2000): SRES-A2 (severe scenario) and SRS-B1 (moderate scenario), and three periods, 2005 to 2009 using real climatic data and two simulated periods, 2041 to 2060 and 2081 to 2100 , were compared. The minimum temperature was used in these scenarios since wetness periods occur mainly at night, when temperatures are lowest. According to the previous climate change projections for Catalonia (Barrera-Escoda and Cunillera 2011), the variation in minimum temperature for the period 2041 to 2060 was considered $+1.4^{\circ} \mathrm{C}$ for scenario $\mathrm{A} 2$ and $+1.0^{\circ} \mathrm{C}$ for scenario $\mathrm{B} 1$; and $+3.5^{\circ} \mathrm{C}$ for scenario $\mathrm{A} 2$ and $+2.3^{\circ} \mathrm{C}$ for scenario $\mathrm{B} 1$ for the period 2081 to 2100 .

To determine the effect of climate change on the risk evolution of brown spot of pear, a simulation was performed comparing levels of disease risk predicted from the observed data from 2005 to 2009 and the levels of disease risk simulated according to the estimated variations in temperature. Data from 5 years (2005 to 2009) from 36 automatic weather stations of the Ministry of Agriculture, Livestock, Fisheries and Food of the Catalan Government were used. Each weather station consisted of a CR10X data logger (Campbell Scientific Ltd., Leicester, UK) with various sensors (leaf wetness, temperature, relative humidity and rain). Weather stations were located in Girona and Lleida regions in Catalonia, the most important areas of pear production. Daily wetness duration and temperature for wetness period data were obtained from the thirty-six stations from April 1 to October 31, covering the pear growing season. Each day, the daily risk (R) and cumulative daily risk (CR) were obtained according to the BSPcast model (Montesinos et al. 1995a; Llorente et al. 2000). With the aim of obtaining an overall 5-year risk for each station, some transformations were performed. It was assumed that values of $\mathrm{CR}<0.4$ indicated low infection risk, $0.4 \leq \mathrm{CR}<0.6$ high infection risk and $\mathrm{CR} \geq 0.6$ very high risk. According to these levels of risk, a new cumulative risk normalized index $(\mathrm{CRN})$ was calculated for each day corresponding to: $\mathrm{CRN}=0$ when $\mathrm{CR}<0.4, \mathrm{CRN}=1$ for $0.4 \leq \mathrm{CR}<0.6$ and $\mathrm{CRN}=2$ for $\mathrm{CR} \geq 0.6$. The frequencies of each CRN value $(0,1$, and 2$)$ were calculated for each weather station over the five years of study. Based on CNR frequencies three partial infection risk $\left(\mathrm{PIR}_{0}, \mathrm{PIR}_{1}, \mathrm{PIR}_{2}\right)$ were determined that corresponded to the first and third quartile for each $\mathrm{CRN}$ value $(0,1$, and 2$)$, and a new value was assigned to PIR 1, 2, and 3, with 3 being the highest infection partial risk. A global infection risk (GIR) was obtained for each weather station according the following equation:

$$
\mathrm{GIR}=\mathrm{PIR}_{0}+\left[\left(\mathrm{PIR}_{1}+\mathrm{PIR}_{2}\right) / 2\right]
$$

The GIR values ranged from 2 to 6 and the frequencies of GIR were calculated for all weather stations. The first and third quartile were used as thresholds for assigning three levels of overall risk to each station as follows: low risk when GIR $<3.5$, high risk when $3.5 \leq$ GIR $<5$ and very high risk if GIR $\geq 5$. The GIR obtained for each weather station was represented in maps using ArcMap 9.2 (ESRI).

\section{RESULTS}

Pathogenicity and aggressiveness of $S$. vesicarium isolates. Twenty-one isolates, corresponding to $19 \%$ of the total evaluated, did not produce lesions on cultivar Conference pear leaves and the 

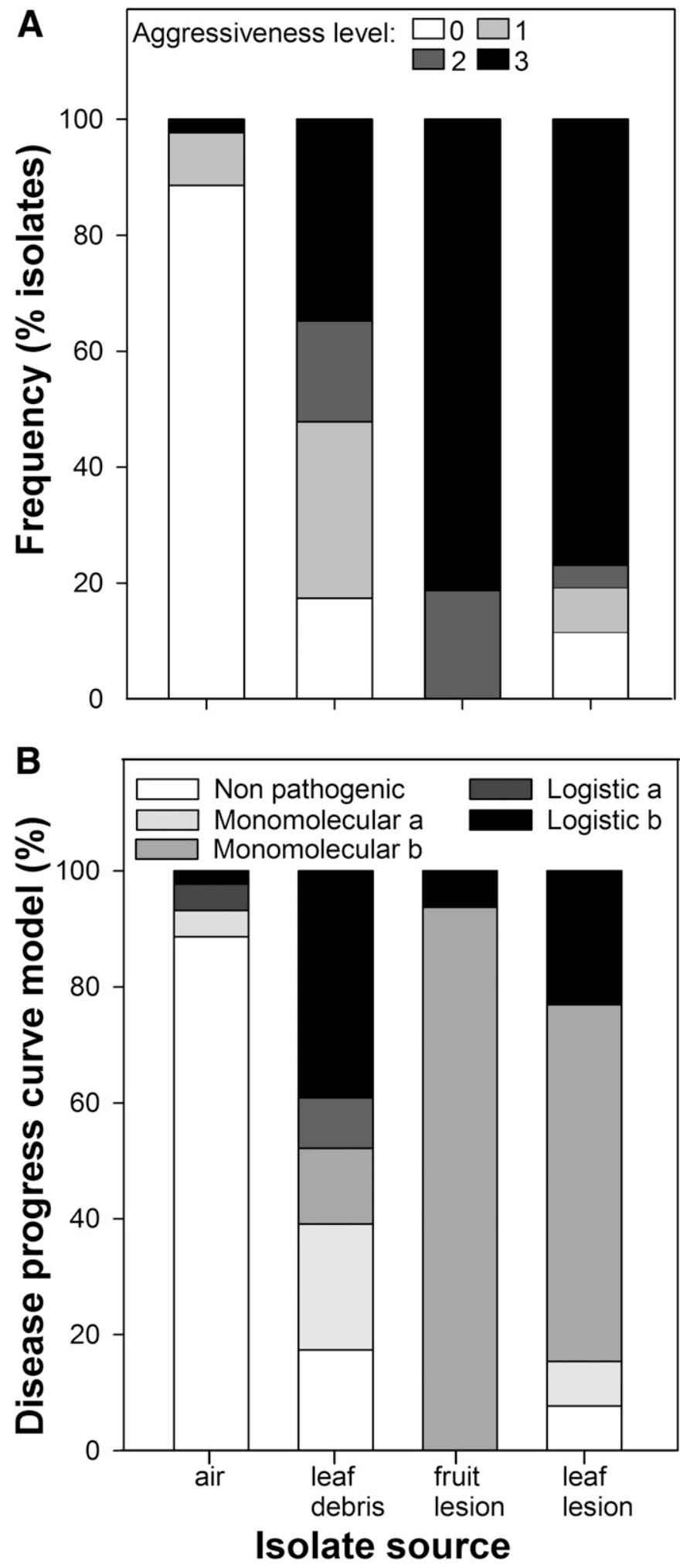

Fig. 1. A, Aggressiveness and B, disease progress curve model type of infection of Stemphylium vesicarium isolates on cultivar Conference pear leaves regarding source of isolation. Four aggressiveness groups were established based on final disease severity $(\mathrm{Sf})(0=\mathrm{Sf} \leq 10 ; 1=10<\mathrm{Sf} \leq 40,2=40<\mathrm{Sf} \leq$ 75 , and $3=\mathrm{Sf}>75 \%$ ). Monomolecular (M) and logistic (L) growth models were fitted to disease progress curves of each isolate obtained from disease severity data through time (0 to 7 days). Model groups also differentiate low (a) or moderate-high (b) aggressiveness of isolates. Nonpathogenic isolates are also included. A total of $104 \mathrm{~S}$. vesicarium isolates recovered from different sources (air, pseudothecia on leaf debris, and leaf and fruit lesions) in northeastern Spanish pear orchards and six isolates from pear orchards in The Netherlands, France, and Portugal were analyzed. Averaged data of three independent experiments are presented. final incidence and severity for these isolates was $0 \%$. This group included nineteen isolates from air inoculum and two isolates from pseudothecia on pear leaf debris. As described previously, isolates that produced necrosis restricted to the inoculation point $(\mathrm{Sf} \leq 10 \%)$ were also considered nonpathogenic, whereas isolates were considered pathogenic when able to infect pear leaves and develop progressive lesions $(\mathrm{Sf}>10)$ (Table 1$)$. About $58.2 \%$ of isolates were pathogenic on cultivar Conference leaves and $41.8 \%$ were nonpathogenic. Most nonpathogenic isolates were recovered from air samples $(84.78 \%)$ and only 8.7 and $6.5 \%$ nonpathogenic isolates were obtained from pseudothecia or leaf lesions, respectively. The pathogenic group included $92.8 \%$ S. vesicarium isolates recovered from lesions on leaves or fruit, $82.6 \%$ isolates from pseudothecia and only $11.4 \%$ isolates from air samples. The isolate from a lesion on a weed leaf collected in a pear orchard (isolate EPS157) was also pathogenic on pear (Table 1).

Analysis of variance indicated a significant $(P<0.0001)$ effect of isolate on final disease incidence and severity. No significant effect of experiment ( $P=0.274$ and $P=0.476$, respectively) was observed, and data from the three independent experiments were combined in the final analysis. Means of disease incidence and severity for each isolate were calculated and are presented in Table 1. Significant differences were observed among isolates in terms of final disease incidence and severity according to Tukey's HSD test (Table 1). Forty percent of isolates produced $100 \%$ final incidence on inoculated leaves and half also produced $100 \%$ final disease severity (such as EPS8, EPS31, EPS35, EPS36, EPS58, EPS60, EPS86, and EPS87 from recovered from lesions and EPS89, EPS91, EPS92, and PRI 890 from leaf debris). Isolates were distributed in the four aggressiveness groups ( 0 , nonpathogenic; 1 , low; 2 , moderate; and 3 , high) described earlier according to Sf values (Table 1). Among the 64 pathogenic $S$. vesicarium isolates, 43 were highly aggressive, 8 moderately aggressive and 13 showed low aggressiveness on cultivar Conference pear leaves. For the source of isolation, $9.1 \%$ of isolates from air samples were pathogenic and low aggressive and only $2.3 \%$ were highly aggressive, whereas $30.4 \%$ isolates from leaf debris showed low aggressiveness and $52.2 \%$ were moderately or highly aggressive. Finally, $76.9 \%$ isolates from pear leaf lesions showed high aggressiveness on cultivar Conference leaves. Isolates from fruit lesions were moderately $(19 \%)$ or highly $(81 \%)$ aggressive (Fig. 1A).

Disease progress over time. Disease intensity over time, expressed as AUDPC, was used to compare isolates. Analysis of variance indicated a significant effect of isolate on AUDPC $(P<$ $0.0001)$, but no effect of experiment $(P=0.246)$ was detected. Significant differences were observed among isolates with AUDPC values ranging from 0 to 550. Stemphylium vesicarium nonpathogenic isolates had AUDPC values lower than 100. Among the isolates with low aggressiveness (group 1), AUDPC ranged from 73.8 to 297.2, whereas the moderately aggressive isolates (group 2) had AUDPC between 272.9 and 384.3. Values of AUDPC for highly aggressive isolates (group 3) ranged from 272.9 to 550 (Table 1). The overlapping AUDPC values in groups with different aggressiveness indicated differences in disease progression through time among $S$. vesicarium isolates sharing similar final severity.

Linear regression analyses showed that the monomolecular model best described the disease progress of $70 \%$ pathogenic $S$. vesicarium isolates, whereas the logistic model best described the disease progress for $30 \%$ pathogenic isolates (Table 1). Pathogenic isolates were distributed differently among the regression models depending on the source of isolation (Fig. 1B). Disease progress of pathogenic $S$. vesicarium isolates recovered from air samples was best described by either monomolecular or logistic model, with most isolates resulting in low disease severity $(\leq 40 \%)$ at the end of the incubation period. Disease progress of $58 \%$ of $S$. vesicarium pathogenic isolates recovered from pseudothecia followed the logistic model, while progress of $42 \%$ followed the monomolecular model. Disease progress of $82 \%$ of pathogenic isolates recovered 
from lesions was best described by the monomolecular model disease progress curves, whereas the logistic model best described the disease progress curve of only $18 \%$ of isolates. In general, the monomolecular model fitted to the majority of disease progress curves of moderately and highly aggressive isolates recovered from lesions, whereas the logistic model fit well to disease progress curves of more than $50 \%$ of pathogenic isolates from air samples and pear leaf debris.

Relationship between isolate origin and pathogenicity and aggressiveness. The results of PCA for the $110 \mathrm{~S}$. vesicarium isolates in relation to the 10 variables analyzed are shown in Table 2. The eigenvalues for the principal components showed that the first three components explained $90 \%$ of the total variance, indicating that three dimensions were necessary to explain the variation among isolates. The first principal component had a positive weight of eigenvectors ( 0.094 to 0.389 ) with the lowest values corresponding to the date of isolation and cultivar. The second component had positive eigenvectors for all variables related to the isolate origin and were negative for pathogenicity- and aggressiveness-related variables. Similarly, the third component had large negative eigenvectors for date and source of isolation, and were highly positive for cultivar and close to zero for most aggressiveness-related variables. Thus, the variation among isolates could be explained by these variables (Figs. 2 and 3). S. vesicarium isolates from various pear cultivars distributed along the different pathogenic/aggressiveness groups shown in Figure 2. Isolates recovered from lesions, leaf debris or air inoculum in cultivar Conference orchards were mixed with the isolates recovered from other pear cultivars in each group. S. vesicarium isolates from France, Portugal, and The Netherlands recovered from lesions or leaf debris, which were highly aggressive on cultivar Conference leaves, grouped together and separately from Spanish isolates in the PC1-PC2-PC3 three-dimension graph (Fig. 3), even though a country variable was not included in the PCA. The isolate from leaf lesions on a weed recovered from a Spanish pear orchard also grouped separately from the other of $S$. vesicarium Spanish isolates in the threedimensional representation (Fig. 3).

Determination of the evolution of brown spot of pear infection risk under scenarios $\mathrm{A} 2$ and $\mathrm{B} 1$ of climate change. Simulations clearly showed that the global infection risk (GIR) will increase with time for the two scenarios evaluated (A2 and B2) (Fig. 4). The number of stations with low disease infection risk will decrease from $27.8 \%$ in 2005 to 2009 to only $8.3 \%$ and $13.9 \%$ in 2081 to 2100 for scenarios A2 and B1, respectively. In contrast, stations with a high infection risk level will be $47.2 \%$ for the 2005 to 2009 period; 38.9 and $41.7 \%$ in scenario A2 for 2041 to 2060 and 2081 to 2100 periods, respectively; and $47.2 \%$ and $38.9 \%$ in scenario B1 for the respective time periods analyzed. Finally, the number of stations with very high infection risk will increase from

TABLE 2. Eigenvectors for the first 3 of the 10 principal components from an analysis of 10 variables for 110 isolates of Stemphylium vesicarium recovered from pear orchards

\begin{tabular}{lccr}
\hline & \multicolumn{3}{c}{ Principal component } \\
\cline { 2 - 4 } Variabley & 1 & 2 & \multicolumn{1}{c}{3} \\
\hline Date & 0.094 & 0.610 & -0.263 \\
Orchard & 0.178 & 0.535 & 0.066 \\
Cultivar & 0.109 & 0.325 & 0.872 \\
Source of isolation & 0.279 & 0.366 & -0.397 \\
Incidence & 0.389 & -0.116 & 0.004 \\
Severity & 0.383 & -0.162 & 0.024 \\
AUDPC & 0.379 & -0.134 & 0.027 \\
DPC model type & 0.371 & -0.118 & 0.067 \\
Pathogenicity & 0.376 & -0.073 & -0.041 \\
Aggressiveness & 0.384 & -0.157 & -0.003 \\
Cumulative variation explained $(\%)$ & 61.74 & 80.98 & 90.07 \\
\hline
\end{tabular}

y Variables are described in Table 1.

${ }^{\mathrm{z}}$ DPC, disease progress curve.
$25.0 \%$ in 2005 to 2009 to $41.7 \%$ in scenario A2 and $33.3 \%$ in scenario B1 for the period 2041 to 2060 . In general, it is expected that $50 \%$ of stations will have a very high risk of infection during the period 2081 to 2100 for the two scenarios. This means that during 2041 to 2060 , under A2 and B1 scenarios, $80.5 \%$ of stations will have high or very high risk; and at the end of 21 st century more than $86 \%$ of stations may have high or very high risks. The increase in the number of locations with very high global infection risk will be higher in Girona (area I) than in Lleida (area II) (Fig. 5).

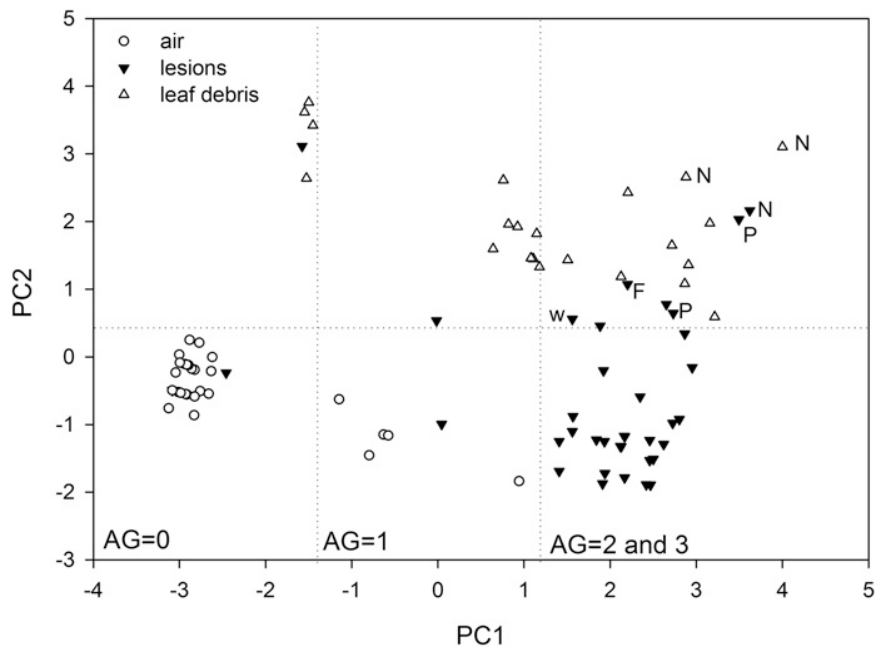

Fig. 2. Principal component analysis (PCA) score plot (PC1 versus PC2) of 110 isolates of Stemphylium vesicarium. Isolate source is designated by shape. Analysis was performed on 10 variables related to origin and pathogenicity/ aggressiveness of isolates listed in Table 1. Aggressiveness groups (AG) are indicated on PC1 axis. Isolates from The Netherlands (N), France (F), Portugal $(\mathrm{P})$, and the isolate recovered from a weed $(\mathrm{W})$ are designated. Averaged data of three independent experiments were used.

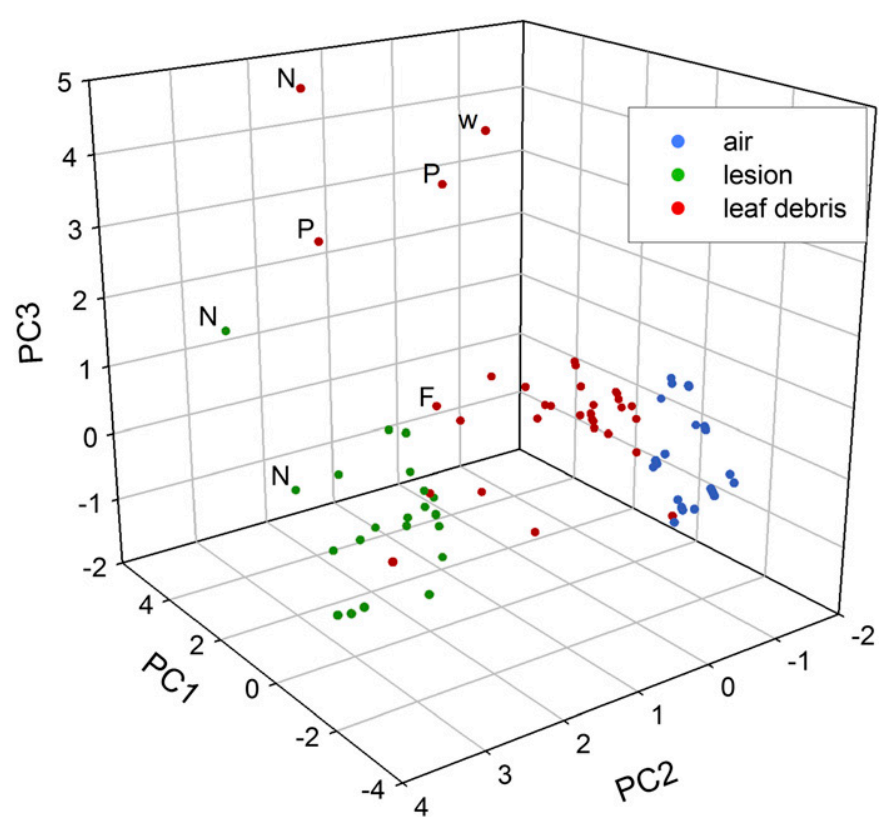

Fig. 3. Three-dimension visualization with coordinates indicating the scores of 110 isolates of Stemphylium vesicarium for three principal components (PC1, $\mathrm{PC} 2$, and PC3) represented in the plot. Isolate source is designated by color and shape. Analysis was performed on 10 variables related to origin and pathogenicity/aggressiveness of isolates listed in Table 1. Isolates from The Netherlands (N), France (F), and Portugal (P), and the isolate recovered from a weed (W) are designated. Averaged data of three independent experiments were used. 


\section{DISCUSSION}

This work comprehensively examines the pathogenicity and aggressiveness structure of $S$. vesicarium populations in pear orchards using a multivariate analysis of disease intensity data. A
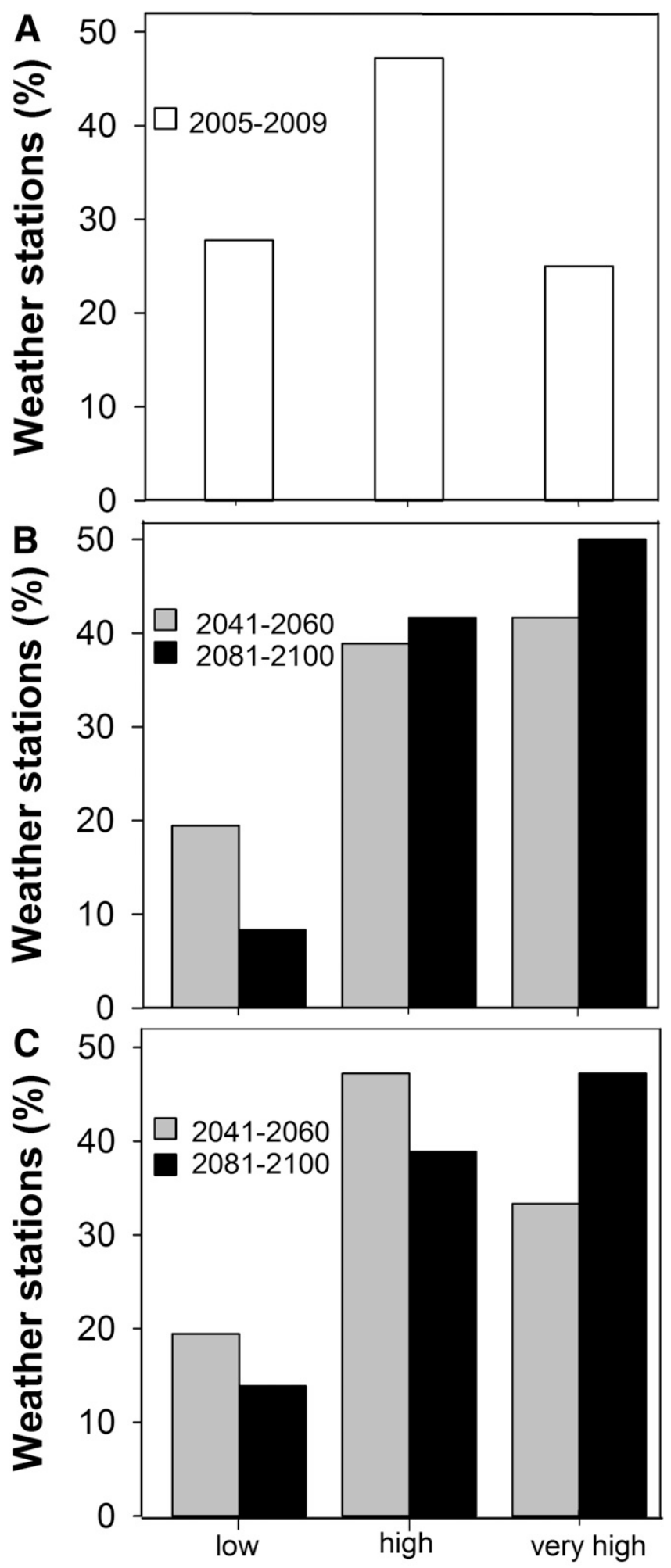

Global infection risk

Fig. 4. Evolution of the global infection risk of brown spot of pear obtained from observed weather data for A, 2005 to 2009, B, simulated under scenario A2, or C, scenario B1 in two periods: 2041 to 2060 and 2081 to 2100. strong relationship between the source of isolation and the pathogenic/aggressiveness profiles of $S$. vesicarium isolates was detected. Most isolates recovered from air samples were nonpathogenic on pear. These isolates were recovered in four different pear orchards growing three pear cultivars (mainly Conference and Passe Crassane) from May to September suggesting that nonpathogenic $S$. vesicarium isolates are ubiquitous and of quantitative importance in air inoculum from pear orchards. Previous studies reported the coexistence of several species of Stemphylium with $S$. vesicarium in pear orchards. These species cannot be easily distinguished from $S$. vesicarium when analyzing spore trap samples for orchard inoculum density determination (Puig et al. 2015b). Monitoring of airborne inoculum is useful to know fluctuations in the inoculum and periods in which the inoculum is low or high, but care must be taken since, based on our results, the actual pathogenic population of $S$. vesicarium could be overestimated. DNA molecular techniques previously described to determine the inoculum potential should be used in combination with spore traps (Köhl et al. 2009; Puig et al. 2015b; Llorente et al. 2011b). The low aggressiveness of most pathogenic isolates recovered from air samples suggests that a part of the $S$. vesicarium air inoculum may not produce severe infections in pear organs during the growing season. Data on pear pathogenic spore flights are essential to determine the inoculum potential and improve forecasting models (Köhl et al. 2009; Rossi et al. 2005a). Our results provide information that should be considered in the model BSPspor that simulates the dynamic of airborne spores using meteorological data (Giosùe et al. 2006; Rossi et al. 2005a). While the reason why a high proportion of airborne conidia are not pathogenic is still unclear, our results suggest that an important amount of inoculum may be produced by populations of $S$. vesicarium that have only the saprophytic phase, since it is not produced in lesions on pear leaves and fruit debris. The few nonpathogenic isolates obtained from pear leaf debris or leaf lesions may also be related to these saprophytic populations.

Most pathogenic isolates recovered from lesions on pear organs were highly aggressive and their corresponding disease increase followed a monomolecular growth pattern. Thus, it is likely that only the pathogenic and highly aggressive inoculum that reaches susceptible host tissues finally leads to infection and rapid disease development. No specificity for pear cultivar was observed among isolates; isolates recovered from Conference and Passe Crassane pear leaf and fruit lesions were similarly aggressive on Conference detached leaves. These two pear cultivars are similarly highly susceptible to the pathogen (Montesinos et al. 1995a). S. vesicarium isolates recovered from leaf debris showed major diversity in pathogenicity and aggressiveness. More than half of pathogenic isolates followed a logistic model in the disease progress curve, indicating the need for an initial period of time for infection after inoculation of host tissues. The nonpathogenic $S$. vesicarium isolates recovered from pseudothecia might have colonized dead leaf debris as saprophytes, whereas the pathogenic ones might have infected pear leaves during the growing season. Isolates that showed high aggressiveness on cultivar Conference pear leaves were recovered from per leaf debris of Abate Fetel, Conference, D. Comice, and Passe Crassane pear cultivars. These results confirm the lack of pear cultivar specificity in $S$. vesicarium.

Only one isolate was recovered from a leaf lesion on a weed in a pear orchard, which was pathogenic and highly aggressive on cultivar Conference leaves. However, the number of isolates from nonhost plants recovered from pear orchards analyzed in this study is too small to draw useful conclusions. More Stemphylium isolates were recovered from lesions on nonhost plants in this study, but an accurate identification based on morphological and molecular data (Puig et al. 2015b) revealed that most of them belonged to other Stemphylium species and thus they were not included in the analysis. S. vesicarium can infect many different plant species such as asparagus, alfalfa, garlic, onion (Chaisrisook et al. 1995; Falloon et al. 1987; Shishkoff and Loorbeer 1989), and European pear 
(Montesinos et al. 1995a). Stemphylium vesicarium isolates from pear show a high degree of host specificity related to the production of host-specific toxins (Singh et al. 1999), and thus S. vesicarium isolates pathogenic to pear recovered from other plant species, such as isolate EPS157, could have been growing as saprophytes or epiphytes on dead weed leaves or dead tissue from infections produced by other agents, rather than causing infection. Dead herbaceous plants growing in pear orchards are potential inoculum sources of $S$. vesicarium that can be saprophytically colonized by the fungus, but the green leaves of lawn grass artificially inoculated with $S$. vesicarium were not colonized (Rossi et al. 2005b). Additionally, Köhl et al. (2009) showed that a very small number of pathogenic $S$. vesicarium isolates were found on symptomless leaves of pear, and when the pathogenic isolates were recovered, the pathogen was an epiphyte or latent within the leaf issue.

Populations of $S$. vesicarium that are pathogenic to pear can colonize fallen pear leaves, fruit and other plant residues in their saprophytic phase, but this saprophytic phase does not affect the ability of $S$. vesicarium to cause infection. Moreover, its aggressiveness depends on where the inoculum is produced in relation to previous lesions. This ability of pathogenic $S$. vesicarium to saprophytically reside on the residues of plants other than pear leads to a more complex epidemiological situation than other fungal diseases such as apple scab (Köhl et al. 2008; MacHardy 1996) and may explain why disease control methods are not always effective. Based on our results, sanitation practices such as leaf litter removal and biocontrol applications of Trichoderma sp. on orchard grounds should be done year round to reduce inoculum production for effective disease control (Llorente et al. 2010; Rossi and Pattori 2009).

Wetness duration and temperature are key factors to trigger $S$. vesicarium infection in pear organs. In this study, the preliminary climate change projections for Catalonia in Northeastern Spain were used, considering the potential changes in temperature. The rationale to use only temperature in these projections is that no studies have been performed to specifically estimate changes in dew formation or relative humidity, and no wetness projections are available. Wetness formation depends on dew and rain.
In the geographic region analyzed, a decrease in annual mean precipitation is expected, but with high spatial and temporal variability. An average reduction in precipitation by $5 \%$ is projected for the 2010-2070 period, and a $14 \%$ reduction by the end of the $21 \mathrm{st}$ century, but these projections are not as robust as those projected for temperature (Barrera-Escoda and Cunillera 2011). An increase in extreme precipitation and dry episodes should be expected. Obviously, the results presented in this work are only an approximation to the possible variations in disease risk due to climate change. From the results obtained herein, the level of disease risk will be high or very high in 2081 to 2100 under the two scenarios A2 (severe) and B1 (moderate) at more than $80 \%$ of the stations. Conditions that are favorable to $S$. vesicarium infections may be lower than those estimated in this work because dry episodes were not considered in the projections. These results suggest that, with climate change, the current warning systems used in disease management could be less useful because of the increase in the frequency of favorable weather conditions for infections, which will result in no savings on fungicide applications. Under these conditions, disease management strategies may require adjustments (Garrett et al. 2006). Additionally, environmental conditions more favorable to infection may lead to shorter disease run and major potential for pathogen evolution (Garrett et al. 2006). As a consequence, the spread of BSP in different pear-growing areas in Europe and other continents is expected to be rapid since the main limitation of expansion is weather conditions, especially temperature and wetness. Pathogens, in particular unspecialized necrotrophs, may extend their host range to cause new disease problems in migrating crops due to climate change (Chakraborty et al. 2000). In addition, the saprophytic capacity of pathogenic $S$. vesicarium can facilitate its adaption to new conditions because the pathogen can survive on leaf debris. The present study shows that the number of locations with very high global infection risk would increase more in the Girona region (area I) than in the Lleida region (area II). However, some problems related to the use of epidemiological models for predicting climate change effects on plant diseases have been described. For example, model inputs have a high degree of uncertainty

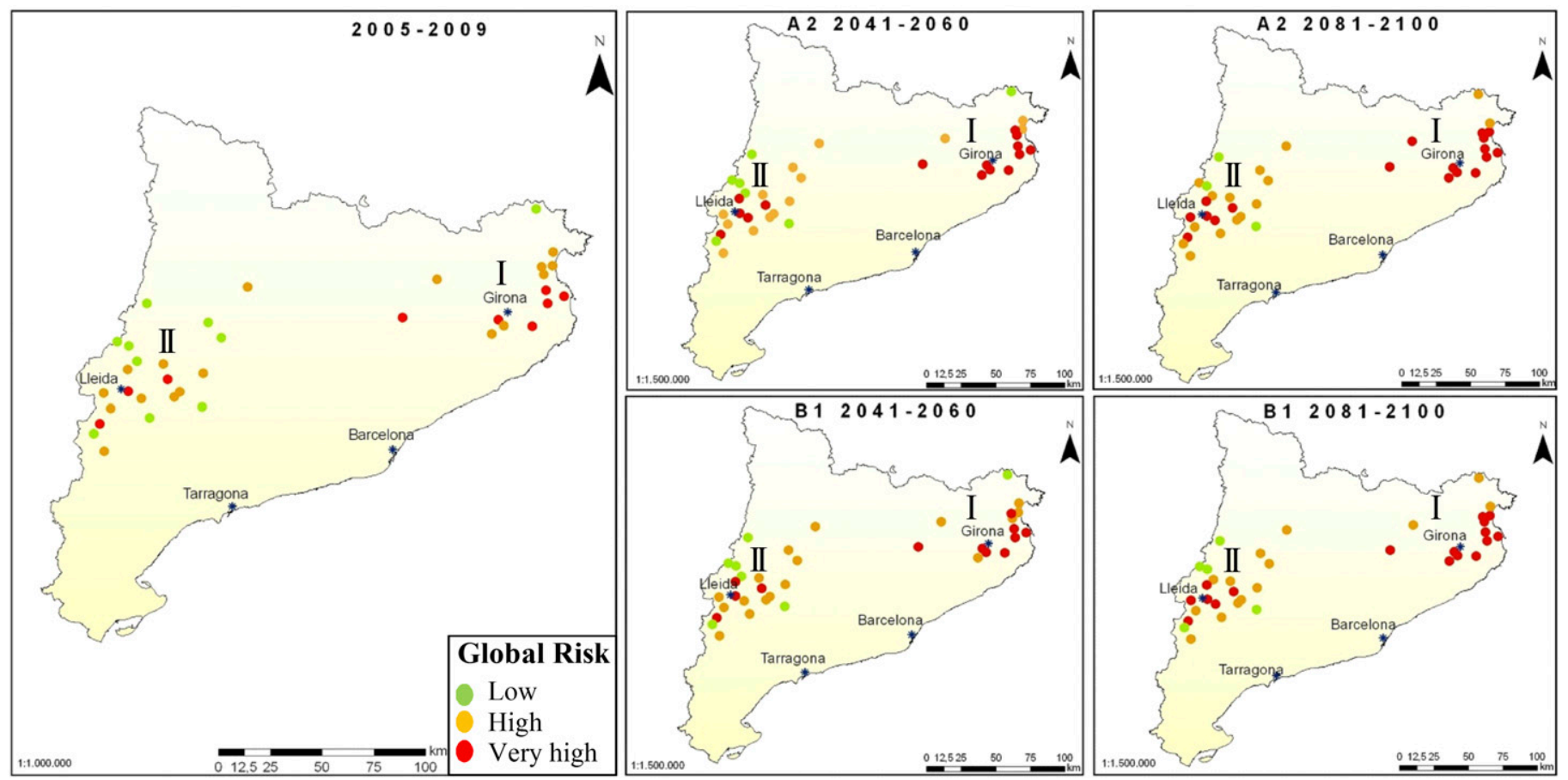

Fig. 5. Localization of weather stations in Catalonia (Northeastern Spain) and global risk variation under two climate change scenarios. Two areas are presented: I corresponds to the Girona region and II corresponds to the Lleida region. For each weather station, the global infection risk of brown spot is presented. Risk was obtained from observed weather data during 2005 to 2009 (left), simulated under scenario A2 (right top) or scenario B1 (right bottom) in two periods: 2041 to 2060 and 2081 to 2100 . 
and the potential for adaption by plants and pathogens is a complicated factor that cannot be ignored in the simulations (Garrett et al. 2006). Nonetheless, the study presented here is a first approximation to draw a general overview of changes in brown spot of pear, but more detailed studies based on new climatic projections are needed. The effect of changes on climatic conditions in different phases of the pathogen, including sporulation, germination and infection rate, may need to be quantified and be included in these projections. This study is an example of how epidemiological models can be used to predict not only the onset of infections but also climate change effects on plant disease.

In the present work, aggressiveness was estimated through disease severity based on lesion size and disease progress over time at the optimal temperature for pathogen infection in susceptible cultivars (Montesinos et al. 1995b) and fungal growth (Montesinos and Vilardell 1992). Pathogenicity and aggressiveness of strains under suboptimal temperatures for $S$. vesicarium germination and infection (below $18^{\circ} \mathrm{C}$ or above $30^{\circ} \mathrm{C}$ ) would result in lower disease severity for most isolates. However, the temperature response may differ among individuals (Milus et al. 2006), and differences among pathogen isolates in some aggressiveness components, such as the latent period, have been reported to be greater under nonoptimal conditions (Pariaud et al. 2009). Moreover, climate change can influence plant disease by altering the biological processes of pathogen and different pathogen stages may vary in their climatic susceptibility. S. vesicarium requires leaf or fruit wetness for infection and sporulation, which most commonly occurs during overnight dewfall. Night temperatures are projected to increase more than day temperatures in climate warming scenarios, thus increasing or decreasing $S$. vesicarium infection and sporulation depending on whether temperatures move closer to or further from the optimal. Further studies on pathogen populations and the relationship between aggressiveness and temperature, especially those focused on climate change effects, could provide complementary information useful for disease management.

Brown spot of pear is an economically emerging disease as well as a complex disease due to the biology and ecological capacity of the causal agent. Multiple epidemiological studies over the last 20 years have led to improved disease management. Knowledge of the epidemiology and ecology of $S$. vesicarium inoculum and its sources, generated in this work, should be included in disease management programs for brown spot of pear. However, more studies are needed to obtain new methods and strategies to decrease inoculum production. Brown spot of pear disease management should include the use of new effective biological control agents and innovative fungicides with high efficacy, such as antimicrobial peptides (Puig et al. 2014, 2015a) to increase the control of S. vesicarium infections, combined with knowledge of how the modifications to climatic parameters due to climate change can affect the geographical distribution and severity of brown spot of pear.

\section{ACKNOWLEDGMENTS}

This research was supported in part by grants from Ministerio de Educación y Ciencia (AGL2009-09829/AGR) of Spain; from the University of Girona (BR10/17 and MPCUdG2016/085); and from the CIRIT of the Catalonian Government (2009SGR812). We thank J. Pereda and P. Vilardell for helpful assistance.

\section{LITERATURE CITED}

Barrera-Escoda, A., and Cunillera, J. 2011. Climate change projection for Catalonia (NE Iberian Peninsula). Part I: Regional climate modeling. Tethys J. Mediterr. Meteorol. Climatol. 8:75-87.

Campbell, C. L., and Madden, L. V. 1990. Introduction to Plant Disease Epidemiology. John Wiley and Sons, New York.

Chaisrisook, C., Stuteville, D. L., and Skinner, D. Z. 1995. Five Stemphylium spp. pathogenic to alfalfa: Occurrence in the United States and time requirements for ascospore production. Plant Dis. 79:369-372.

Chakraborty, S., Tiedemann, A. V., and Teng, P. S. 2000. Climate change: Potential impact on plant diseases. Environ. Pollut. 108:317-326.
Coakley, S. M., Scherm, H., and Chakraborty, S. 1999. Climate change and plant disease management. Annu. Rev. Phytopathol. 37:399-426.

Elad, Y., and Pertot, I. 2014. Climate change impacts on plant pathogens and plant diseases. J. Crop Improv. 28:99-139.

Falloon, P. G., Falloon, L. M., and Grogan, R. G. 1987. Etiology and epidemiology of Stemphylium leaf spot and purple spot of asparagus in California. Phytopathology 77:407-413.

Garrett, K. A., Dendy, S. P., Frank, E. E., Rouse, M. N., and Travers, S. E. 2006. Climate change effects on plant disease: Genomes to ecosystems. Annu. Rev. Phytopathol. 44:489-509.

Giosùe, S., Rossi, V., Bugiani, R., and Mazzoni, C. 2006. Modelling dynamics of airborne conidia of Stemphylium vesicarium, the causal agent of brown spot of pear. IOBC WPRS Bull. 29:169-176.

Hudson, H. J. 1971. The development of the saprophytic fungal flora as leaves senesce and fall. Pages 447-455 in: Ecology of Leaf Surface Micro-Organisms. T. F. Preece and C. H. Dickinson, eds. Academic Press, London, New York.

Köhl, J., Groenenboom-de Haas, B., Goossen-van de Geijn, H., Speksnijder, A., Kastelein, P., Hoog, S., and Gerrits van den Ende, B. 2008. Pathogenicity of Stemphylium vesicarium from different hosts causing brown spot in pear. Eur. J. Plant Pathol. 124:151-162.

Köhl, J., Groenenboom-de Haas, B. H., Kastelein, P., Rossi, V., and Waalwijk, C. 2009. Quantitative detection of pear-pathogenic Stemphylium vesicarium in orchards. Phytopathology 99:1377-1386.

Llorente, I., and Montesinos, E. 2002. Effect of relative humidity and interrupted wetness periods on brown spot severity of pear caused by Stemphylium vesicarium. Phytopathology 92:99-104.

Llorente, I., and Montesinos, E. 2004. Development and field evaluation of a model to estimate the maturity of pseudothecia of Pleospora allii on pear. Plant Dis. 88:215-219.

Llorente, I., and Montesinos, E. 2006a. Brown spot of pear: An emerging disease of economic importance in Europe. Plant Dis. 90:1368-1375.

Llorente, I., Montesinos, E., and Vilardell, A. 2006b. Infection potential of Pleospora allii and evaluation of methods for reduction of the overwintering inoculum of brown spot of pear. Plant Dis. 90:1511-1516.

Llorente, I., Moragrega, C., Ruz, L., and Montesinos, E. 2011b. An update on control of brown spot of pear. Trees (Berl.) 26:239-245.

Llorente, I., Vilardell, A., Vilardell, P., Pattori, E., Bugiani, R., Rossi, V., and Montesinos, E. 2010. Control of brown spot of pear by reducing the overwintering inoculum through sanitation. Eur. J. Plant Pathol. 128:127-141.

Llorente, I., Vilardell, P., Bugiani, R., Gherardi, I., and Montesinos, E. 2000. Evaluation of BSPcast disease warning system in reduced fungicide use programs for management of brown spot of pear. Plant Dis. 84:631-637.

Llorente, I., Vilardell, P., and Montesinos, E. 2011a. Evaluation of a revision of the BSPcast decision support system for control of brown spot of pear. Phytopathol. Mediterr. 50:139-149.

MacHardy, W. E. 1996. Apple Scab Biology, Epidemiology, and Management. American Phytopathological Society, St. Paul, MN.

Milus, E. A., Seyran, E., and McNew, R. 2006. Aggressiveness of Puccinia striiformis $\mathrm{f}$. sp. tritici isolates in the South-Central United States. Plant Dis. 90:847-852.

Montesinos, E., Moragrega, C., Llorente, I., and Vilardell, P. 1995a. Susceptibility of selected European pear cultivars to infection by Stemphylium vesicarium and influence of leaf and fruit age. Plant Dis. 79:471-473.

Montesinos, E., Moragrega, C., Llorente, I., Vilardell, P., Bonaterra, A., Ponti, I., Bugiani, R., Cavanni, P., and Brunelli, A. 1995b. Development and evaluation of an infection model for Stemphylium vesicarium on pear based on temperature and wetness duration. Phytopathology 85:586-592.

Montesinos, E., and Vilardell, P. 1992. Evaluation of FAST as a forecasting System for scheduling fungicide sprays for control of Stemphylium vesicarium on pear. Plant Dis. 76:1221-1226.

Nakićenović, N., Alcamo, J., de Vries, B., Fenhann, J., Gaffin, S., Gregory, K., Griibler, A., Jung, T. Y., Kram, T., Lebre La Rovere, E., Michaelis, L., Mori, S., Morita, T., Pepper, W., Pitcher, H., Price, L., Riahi, K., Roehrl, A., Rogner, H.-H., Sankovski, A., Schlesinger, M., Shukla, P., Smith, S., Swart, R., van Rooijen, S., Victor, N., and Dadi, Z. 2000. Special Report on Emissions Scenarios: A Special Report of Working Group III of the Intergovernmental Panel on Climate Change. Cambridge University Press, Cambridge, UK.

Neter, J., Wasserman, W., and Kutner, M. H. 1985. Applied Linear Statistical Models, 2nd ed. Irwin Publishing, Homewood, IL.

Pariaud, B., Ravigné, V., Halkett, F., Goyeau, H., Carlier, J., and Lannou, C. 2009. Aggressiveness and its role in the adaptation of plant pathogens. Plant Pathol. 58:409-424.

Pattori, E., Rossi, V., Bugiani, R., and Giosue, S. 2006. Virulence of Stemphylium vesicarium isolates from pear and other host species. IOBC WPRS Bull. 29:195-205

Puig, M., Moragrega, C., Ruz, L., Montesinos, E., and Llorente, I. 2014. Postinfection activity of synthetic antimicrobial peptides against Stemphylium vesicarium on pear. Phytopathology 104:1192-1200. 
Puig, M., Moragrega, C., Ruz, L., Montesinos, E., and Llorente, I. 2015a. Controlling brown spot of pear by a synthetic antimicrobial peptide under field conditions. Plant Dis. 99:1816-1822.

Puig, M., Ruz, L., Montesinos, E., Moragrega, C., and Llorente, I. 2015 b. Combined morphological and molecular approach for identification of Stemphylium vesicarium inoculum in pear orchards. Fungal Biol. 119:136-144.

Rossi, V., Bugiani, R., Giosué, S., and Natali, P. 2005a. Patterns of airborne conidia of Stemphylium vesicarium, the causal agent of brown spot disease of pears, in relation to weather conditions. Aerobiologia 21:203-216.

Rossi, V., and Pattori, E. 2009. Inoculum reduction of Stemphylium vesicarium, the causal agent of brown spot of pear, through application of Trichoderma-based products. Biol. Control 49:52-57.
Rossi, V., Pattori, E., and Bugiani, R. 2007. Sources and seasonal dynamics of inoculum for brown spot disease of pear. Eur. J. Plant Pathol. 121: 147-159.

Rossi, V., Pattori, E., Giosue, S., and Bugiani, R. 2005b. Growth and sporulation of Stemphylium vesicarium, the causal agent of brown spot of pear, on herb plants of orchard lawns. Eur. J. Plant Pathol. 111:361-370.

Shishkoff, N., and Loorbeer, J. W. 1989. Etiology of Stemphylium leaf blight of onion. Phytopathology 79:301-304.

Singh, P., Bugiani, R., Cavanni, P., Nakajima, H., Kodama, M., Otani, H., and Kohmoto, K. 1999. Purification and biological characterization of hostspecific SV-toxins from Stemphylium vesicarium causing brown spot of European pear. Phytopathology 89:947-953. 